\title{
Effect of complex circuit exercises on cd34/cd45 stem cells and their relation to health efficiency for water polo players "Dr/ Alaa Sayed Nabeh
}

\section{Abstract}

Purpose: Complex circuit exercises are valuable tools for enhancing the water polo players' skills; the aim of this study was to determine the effect of Complex circuit exercises on cd34+/cd45 stem cells, certain physical variables and composite Skillful Performances among water polo players.

Methods:Twenty water polo players were divided into two groups, The experimental group comprised of (10) water polo player in the age groups of 18-21 years from El Zohor club. The subjects in this group underwent a Complex circuit exercises program comprising of various weight and Plyometric exercises in addition to water exercises for a period of (2) months. The control group comprised of (10) water polo players as the same age for the experimental group. Parameters assessed the height, weight, power, strength, training age and Blood Sample were collected from an antecubital vein into vacuum tubes to measure the $\mathrm{Cd} 34+/ \mathrm{Cd} 45$ Stem Cells. All subjects were free of any disorders known to affect performance, such as bone fractures, osteoporosis, diabetes and cardiovascular disease. The participants did not report use of any anti-seizure drugs, alcohol and cortoon consumption, neither smoking cigarette. And all participants were fully informed about the aims of the study, and gave their voluntary consent before participation. The measurement procedures were in agreement with the ethical human experimentation. All statistical analyses were calculated by the SPSS statistical package. The results are reported as means and standard deviations (SD). Differences between two groups were reported as mean difference $\pm 95 \%$ confidence intervals (mean diff $\pm 95 \%$ ). T test for samples was used to determine the differences in the parameters between the two groups. And Pearson correlations between all variables was used, the $\mathrm{p}<0.05$ was considered as statistically significant.

${ }^{*}$ Faculty of physical education, Helwan University, Egypt

Assiut Journal For Sport Science Arts 
Results:The results indicated the significant increase between the pre and post measures for the experimental group in accounting of cd34+/cd45 stem cells, power, strength, and composite Skillful Performances.

Conclusions:The results indicate that a two months of Complex circuit exercises program can improve physical, composite skills and stem cells for water polo players.

Key words:Complex circuit exercises $-\mathrm{Cd} 34+/ \mathrm{Cd} 45$ Stem Cells, water polo

\section{Introduction:}

Complex circuit training is like the "musical chairs" of the exercise world. Although it may look chaotic to a casual observer, there is method to the madness that constitutes this intense form of exercise. While its pace may leave the heart of the player beating hard and his body sweaty (in general not water polo), because he can adapt exercises to his current level of fitness, as long as he takes the right health and safety precautions, circuit training is appropriate for almost everyone.

The core objectives of circuit training are to increase muscle strength, endurance, flexibility and coordination. Whether you accomplish one or all of these objectives depends on how you structure your training. Each training session usually includes a combination of both aerobic exercise and strength training. However, circuit training can include whatever type of exercise you want, in whatever combination helps you accomplish your exercise goals. This could mean your circuit training routine includes only aerobics or only strength training.

The physical demands of water polo competitions are high, involving the aerobic and anaerobic a lactic and lactic metabolisms, and are also affected by age, sex, level of training and technical and tactical models utilized in relation to the adversary.

Water polo is a sport of skill, speed, and power. Skill is improved by long years of practice and experience under 
the guidance of expert coaching. Traditionally, water polo players have relied on the same practice for the development of speed and power. (Bernd \&Emil 2007)

Strength and power are important aspects of fitness, sport and everyday activity. However, much debate remains as to how these two qualities should be assessed. Much of the debates originates from the definition of strength and power and the different terminology used across laboratories. Sale (1991) defined strength as the force exerted under a given set of conditions during a maximal voluntary contraction (MVC). Sale continued to define power as the rate at which mechanical work is performed under a specified set of conditions, or the product of force and velocity.

Both definitions imply that strength and power are defined by conditions such as velocity, contraction type, and posture and movement pattern specificity. That is, strength for one task may not imply strength for another. An associated problem with this is that strength and power are quite often measured in contexts dissimilar to the environment in which functional strength and power are needed. (Fatourous, et al. 2000)

Coaches and athletes have modified training method in an attempt to develop explosive power, some researchers showed that combining Plyometric with weight training could have more effectiveness, more specifically, Complex circuit exercises alternates biomechanically similar high load weight training exercises with Plyometric exercises, set for set, in the same workout.

Types of training methods which used to enhancement of strength and power are:

* (Individual training)

* Olympic lifts only

* Plyometric exercises only

* (Combination training)

* Train both Olympic and Plyometric exercises during two different training sessions

* (Complex training)

* Train both Olympic and Plyometric exercises during the same training session * (Complex circuit exercises) 
* A series of Olympic and/or Plyometric exercises coupled together to form a set.

Complex circuit exercises protocols offer a novel exercise sequence based on the principle that exercise for the development of reactive ability can be fulfilled in a background of heightened CNS excitability, brought about by preliminary fulfillment of exercise requiring great power. Repeated bouts of structured bodily exertion requiring energy expenditure above resting levels result in the occurrence of multiple molecular and cellular events leading to several functional changes and providing countless health-related benefits. The disruption of the dynamic equilibrium of body homeostasis is the sine qua non of the exercise-induced adaptations at the level of the cardiovascular and neuromuscular systems.

Skeletal muscle is a dynamic tissue able to adapt to various physiological conditions. The ability of skeletal muscle to regenerate is mainly due to small mononucleotide cells, called the satellite cells, located between the basal lamina and the sarcolemma of muscle fibers. Satellite cells are considered as skeletal muscle stem cells as they can reenter the cell cycle to generate differentiated cells and new undifferentiated myogenic precursor cells, allowing the renewal of their own population (Hawke, 2005).

Exercise is one of the most powerful nonpharmacological strategies, which is able to affect nearly all cells and organs in the body. In this context, a new research avenue focusing on the action of exercise on adult stem cells has emerged during the last decade. Changes in the behavior of adult stem cells from different regions including skeletal muscle and the cardiovascular system have been shown to occur in response to exercise training. Through its action on adult stem cells, exercise may act on the regenerative potential of tissues by altering the ability to generate new stem cells and differentiated cells that are able to carry out tissue-specific functions. (Kadi, \& Thornell.2000)

The aim of this study was to determine the effect of Complex circuit exercises on cd34+/cd45 stem cells, certain 
physical variables and health efficiency of water polo players.

\section{Material and Methods}

Experimental Approach to the Problem

Two groups

(experimental and control) performed a pre and post training designed intervention in which Standing Long Jump Test (SLJ), Seated Medicine Ball Throw (SMBT) , leg strength (LS) back strength (BS) by dynamometer , Dynamic strength test (DST) and composite Skillful Performances (CSP) were recorded. The experimental group (EG) (10 water polo players) trained 1 hour per day 3 times a week on Complex circuit exercises besides the water polo drills for twelve weeks. The control group (10 water polo players) continued their normal training, while the experimental group completed a Complex circuit exercises program to see whether this type of training modality would have a positive or negative or no effect on (SLJ), (SMBT), (LS), (BS), (DST), (CSP), CD34/CD45 stem cells and health efficiency.

\section{Methods.}

$\begin{array}{cl}\text { Twenty } & \text { water polo } \\ \text { player. Divided } & \text { into two }\end{array}$ groups, the experimental group comprised of (10) water polo player in the age groups of 1821 years from El zohor club. The subjects in this group underwent a Complex circuit exercises program comprising of various weight and Plyometric exercises and under water exercises for (2) months. The control group comprised of (10) water polo players as the same age for the experimental group. Parameters assessed the high, weight, power, strength, training age and Blood Sample were collected from an antecubital vein into vacuum tubes to measure the Cd34+/Cd45 Stem Cells. All subjects were free of any disorders known to affect performance, such as bone fractures, osteoporosis, diabetes and cardiovascular disease. The participants did not report use of any antiseizure drugs, alcohol and cortoon consumption, neither smoking cigarette. And all participants were fully informed about the aims of the 
study, and gave their voluntary consent before participation. The measurement procedures were in agreement with the ethical human experimentation.

\section{Training Protocol}

The 8-weeks in-season training program consisted of a set of resistance exercises followed by a series of Plyometric exercises. All sets of the weights exercise with a recovery of 60 seconds/set.
This is followed by a three minute rest before performing all sets of the matched Plyometric exercise with a recovery of 90 second/set. Load intensity was ranged between $50-60 \%$.Beside the complex circuit exercises they also had done some exercises inside the water. The Complex circuit exercises program is described in Table 1.

\section{Table (1)}

Complex circuit exercises protocol.

\begin{tabular}{|c|c|c|c|}
\hline Complex & Exercise & Reps & Rest/Set \\
\hline Station 1 & Squats & $3 \times 12 \mathrm{RM}$ & 60 seconds \\
\hline Station 2 & Vertical Jumps & $3 \times 10$ & 90 seconds \\
\hline Station 3 & Bench Press & $3 \times 12 \mathrm{RM}$ & 60 seconds \\
\hline Station 4 & Medicine ball chest pass & $3 \times 10$ & 90 seconds \\
\hline Station 5 & Barbell Lunge & $3 \times 12 \mathrm{RM}$ & 60 seconds \\
\hline Station 6 & Step Jumps & $3 \times 10$ & 90 seconds \\
\hline Station 7 & Lat Pull down & $3 \times 12 \mathrm{RM}$ & 60 seconds \\
\hline Station 8 & Medicine ball overhead pass & $3 \times 10$ & 90 seconds \\
\hline Station 9 & Abdominal crunches & $3 \times 12 \mathrm{RM}$ & 60 seconds \\
\hline Station 10 & Medicine ball sit up and throw & $3 \times 10$ & 90 seconds \\
\hline Station 11 & Decline press & $3 \times 12 \mathrm{RM}$ & 60 seconds \\
\hline Station 12 & Zigzag drill & $3 \times 10$ & 90 seconds \\
\hline Station 13 & Scissors move $*$ & $3 * 10$ & 60 seconds \\
\hline Station 14 & A changing scissors move* & $3 * 10$ & 60 seconds \\
\hline Station 15 & English Jump* & $3 * 10$ & 60 seconds \\
\hline Station 16 & Resistance exercises* & $3 * 10$ & 90 seconds \\
\hline \multicolumn{4}{|c|}{$\begin{array}{l}\text { * Water Exercises: } \\
\text { Testing Procedures }\end{array}$} \\
\hline \multicolumn{2}{|c|}{ Assiut Journal For Sport Science Arts } & & \\
\hline
\end{tabular}


training program Tests followed a general warm-up that consisted of running, calisthenics, and stretching Static strength test (LS) (BS)

A back dynamometer was used to measure the static leg strength. The subjects stood on the dynamometer platform and crouched to the desired leg bend position, while strapped around the waist to the dynamometer. At a prescribed time they exerted a maximum force straight upward by extending their legs. They kept their backs straight, head erect and chest high. 3 trials were allowed to the subjects and the best score was taken. Subjects had a rest between the trials.

Standing Long Jump Test (SLJ):

The subject stands behind a line marked on the ground with feet slightly apart. A two foot take-off and landing is used, with swinging of the arms and bending of the knees to provide forward drive. The subject attempts to jump as far as possible, landing on both feet without falling backwards. Three attempts are allowed.

Seated Medicine Ball Throw (SMBT):
The subject stand with their back to a wall, facing the area to which the ball is to be thrown, and with the feet extended and slightly apart. The ball is held with the hands (two hands) on the side and slightly behind the center. The ball is brought to the chest, and then thrown vigorously out as far as possible. The back should remain in contact with the wall at all times. Three attempts are allowed. The distance from the wall to where the ball lands are recorded. The measurement is recorded to the nearest $10 \mathrm{~cm}$. The best result of three throws is used.

\section{Dynamic strength test (DST)}

A barbell and free weights were used to measure dynamic strength. A suitable starting weight, close to, but below the subjects' estimated maximum lifting capacity was selected. If one repetition was completed, the experimenter added weight to the barbell until the subject reached his maximum capacity. Both legs were tested (Legs Push).

The weight increments were usually 5,2 and $1 \mathrm{~kg}$ during the period of measurement. 
Composite

Skillful

Performances (CSP)

the water polo player move forward and make the scissors move while changing its direction then approach a teammate in order to perform the English jump then push back towards the beginning point, measuring the time between start and movement ending

\section{Blood Samples:}

In the rest period, blood drawn by venipuncture and used the Flow cytometry for counting and examining microscopic particles, such as CD34/CD45

Statistical analysis

Table (2)

Mean \pm SD for (SMBT), (VJ), (SLJ), (PLDCK) and (VMA) for the
control and experimental groups

Mean \pm SD for (SMBT), (VJ), (SLJ), (PLDCK) and (VMA) for the
control and experimental groups

\begin{tabular}{|c|c|c|c|c|c|c|c|c|}
\hline \multirow{2}{*}{ Variables } & \multirow[t]{2}{*}{$\overline{\text { Unit }}$} & \multicolumn{3}{|c|}{ Control } & \multicolumn{3}{|c|}{ Experimental } & \multirow{2}{*}{$\begin{array}{c}T \text { test } \\
\text { between } \\
\text { two } \\
\text { groups } \\
\end{array}$} \\
\hline & & pre & post & T test & pre & post & T test & \\
\hline SLJ & $\mathrm{Cm}$ & $\begin{array}{l}196.23 \\
\pm 3.68\end{array}$ & $\begin{array}{l}199.11 \\
\pm 4.15\end{array}$ & $\begin{array}{l}\text { Not } \\
\text { Sign }\end{array}$ & $\begin{array}{c}197.65 \pm \\
3.54\end{array}$ & $\begin{array}{l}207.23 \\
\pm 5.32\end{array}$ & Sign & $\overline{\text { Sign }}$ \\
\hline SMBT & Meter & $\begin{array}{c}6.21 \pm \\
0.39\end{array}$ & $\begin{array}{c}6.58 \pm \\
0.47\end{array}$ & $\begin{array}{l}\text { Not } \\
\text { Sign }\end{array}$ & $\begin{array}{c}6.23 \pm \\
0.16\end{array}$ & $\begin{array}{c}6.92 \pm \\
0.54\end{array}$ & Sign & Sign \\
\hline LS & Kilogram & $\begin{array}{r}75.26 \\
\pm 3.57\end{array}$ & $\begin{array}{r}76.29 \\
\pm 3.99\end{array}$ & $\begin{array}{l}\text { Not } \\
\text { Sign }\end{array}$ & $\begin{array}{c}77.21 \pm \\
3.62\end{array}$ & $\begin{array}{l}79.86 \\
\pm 4.06\end{array}$ & Sign & Sign \\
\hline BS & Kilogram & $\begin{array}{l}51.34 \\
\pm 3.91\end{array}$ & $\begin{array}{l}53.03 \\
\pm 3.52\end{array}$ & $\begin{array}{l}\text { Not } \\
\text { Sign }\end{array}$ & $\begin{array}{c}52.09 \pm \\
3.11\end{array}$ & $\begin{array}{l}55.74 \\
\pm 3.72\end{array}$ & Sign & Sign \\
\hline DST & Kilogram & $\begin{array}{c}80.11 \\
\pm 6.34 \\
\end{array}$ & $\begin{array}{r}80.56 \\
\pm 5.61 \\
\end{array}$ & $\begin{array}{l}\text { Not } \\
\text { Sign }\end{array}$ & $\begin{array}{c}79.67 \pm \\
5.48\end{array}$ & $\begin{array}{r}84.83 \\
\pm 5.55 \\
\end{array}$ & Sign & Sign \\
\hline CSP & Second & $\begin{array}{c}4.57 \pm \\
0.21\end{array}$ & $\begin{array}{c}4.49 \pm \\
0.33\end{array}$ & $\begin{array}{l}\text { Not } \\
\text { Sign }\end{array}$ & $\begin{array}{c}4.56 \pm \\
0.34\end{array}$ & $\begin{array}{c}4.08 \pm \\
0.21\end{array}$ & Sign & Sign \\
\hline CD34/CD45 & $\begin{array}{l}\text { Count( } \\
\mathrm{N})\end{array}$ & $\begin{array}{c}9.98 \pm \\
1.17\end{array}$ & $\begin{array}{l}10.11 \\
\pm 1.67\end{array}$ & $\begin{array}{l}\text { Not } \\
\text { Sign }\end{array}$ & $\begin{array}{c}10.07 \pm \\
1.21\end{array}$ & $\begin{array}{r}12.75 \\
\pm 1.62\end{array}$ & Sign & Sign \\
\hline
\end{tabular}

All statistical analyses were calculated by the SPSS statistical package. The results are reported as means and standard deviations (SD). groups were reported as mean difference $\pm 95 \%$ confidence intervals (mean diff $\pm 95 \%$ ). $\mathrm{T}$ test for samples was used to determine the differences in the parameters between the two groups. And Pearson correlations between all variables was used, the $\mathrm{p}<0.05$ was considered as statistically significant.

\section{Results} Differences between two 
Table (2) Shows the mean scores and percentage changes for on ((SLJ), (SMBT), (LS), (BS), (DST), (CSP) and CD34/CD45 stem cells for the control and experimental groups. The t-test showed a significant changes between pre-and post-training scores for all variables $(\mathrm{P} \leq 0.05)$ for experimental group .however no significant differences was shown between pre-and posttraining scores for all variables for control group $(\mathrm{P} \geq 0.05)$. We can see that the differences between the results in the control group are small while in the experimental group are big like for example in (SLJ) for the experimental, the result was $(197.65 \pm 3.54)$ and after the experiment became (207.23 \pm 5.32 ).

\section{Discussion}

The purpose of this study was to determine if Complex circuit exercises can enhance SLJ), (SMBT), (LS), (BS), (DST) (CSP) and CD34/CD45 among water polo players

The results indicate that Complex circuit exercises is capable of improving the physical - skill variables and counting of CD34/CD45 stem cells.

There are a number of potential explanations for these findings.

In the fact that Complex circuit exercises stimulates the neuromuscular system. That is, it activates both the muscular fibers and the nervous system, so that slow-twitch fibers behave like fast-twitch fibers. (Chu, 1998). Furthermore, resistance training increases motor neuron excitability and reflex potentiation, which may lead to better training conditions for subsequent Plyometric exercises (Ebben, \& Watts, 1998); higher EMG activity was discovered in the hamstring muscles during depth jumping indicates that more fast-twitch fibers were being recruited, which in time could have provided more propulsive power. This fact may have contributed to the increments observed in the present study. It is postulated that the resistance exercise will have a performance enhancing effect on the Plyometric activity. (Ebben, \& Blackard, 1998). Another explanation is that the muscles were involved 
in a very rapid switch from the eccentric phase to the concentric phase (Stretchshortening cycle). This SSC decreases the time of the amortization phase that in turn allows for greater than normal power production. (Hamza, 2008)

According to Rahimi, \& Behpur, (2005) In the SSC the muscles undergo transition energy (from eccentric to concentric muscle action), so that to train and enhance this transition phase requires a Complex circuit exercises, such as the programs used in this study. Thereby, weight training increases muscular strength and plyometric training exploits the SSC; therefore, the strength acquired by the weight training protocols will be used in this cycle (SSC) to produce a more forceful concentric muscle action and increase anaerobic power. The results of this study showed that Complex circuit exercises has a more significant effect.

A number of studies demonstrate the effectiveness of Plyometric compared to non-exercising control groups.
(Blakey et al., 1987; Diallo et al., 2001), other studies demonstrate an enhancement of motor performance associated with Plyometric training combined with Weight training or the superiority of Plyometric, compared to other methods of training (Adams et al., 1992; McLaughlin, 2001; Vossen et al., 2000). The evidence indicates that the combination weight training and Plyometric are effective. the Muscles will best respond to Complex circuit exercises when utilized through their full range of motion, this is also beneficial to the water polo practitioner as techniques are executed through their full range of motion and therefore the training program consider to train in this manner.

Research has found the Complex circuit exercises can be beneficial to athletic performance (Comyns, et al. 2007; Evans, et al. 2000). While the opposite has also been reported. (Jones, and Lees, 2003)

The results of this investigation are in accordance with previous studies (Adams, 
et al. 1992; Sale, 1991; Cavagna, 1977; Cavagna, et al. 1968), showing that a combined program of weightlifting and Plyometric can significantly increase the power and strength.

In their article Hamza, (2008) suggested that a greater muscular power may be related to a more effective and contributing to the improvement in the lung technique for water polo players.

Competitive water polo players can obviously benefit from an increase in strength. Stronger muscles can be faster muscles (Chui, 1964; Fox, et al.1988). Studies have shown increases in contraction speed when weight training was used in conjunction with sport skill practice (Dengel, et al.1987). Improved sprint performance subsequent to weight training demonstrates the application of strength to speed production (Delecluse, 1997).

Another important result of our study is the significant reduction in the CD34/CD45 stem cells secretions after the training program; these findings show the quality of the training program design.

Several mechanisms may contribute to increase of CD34/CD45 stem cells followed 8- weeks of the Complex circuit exercises program. Concerning the adaptations to strength and power training, (Ferrauti et al. 2001) main factors are referred to in the literature: neural and hypertrophic. (Ransford 1982) and resistance training is more likely to be associated with increases in fiber crosssectional area.

A number of studies have shown that exercise improves the function and regeneration of the cardiovascular system and skeletal muscle by activating and mobilizing organ-resident stem cells (Crameri, et al. 2007; Petrella, et al. 2006)or by recruiting blood-circulating stem or progenitor cells (Adams, et al. 2004 ; Sandri, et al. 2005).

Kadi, \& Thornell. (2000) suggest that physical exercise can exert powerful effects on different stem cell niches by altering their microenvironment. Currently, 
the mechanisms behind the maintenance of a quiescent state within each stem cell niche as well as the exact signals leading to the proliferation of stem cells following exercise are not fully understood.

\section{Practical Applications}

Upper and lower body explosively levels of water polo players can be improved with a combined program of Plyometric and resistance training. These power level improvements are usually seen as essential in water polo performance. The use of Complex circuit exercises which contain of both resistance and Plyometric training in the same workout is an adequate strategy of training process organization, having highly positive effects on performance level and CD34/CD45 stem cells.

\section{References.}

1- Adams V, Lenk K, Linke A, Lenz D, et al. (2004). Increase of circulating endothelial progenitor cells in patients with coronary artery disease after exercise-induced ischemia. Arterioscler Thromb Vasc Biol. 24:684-90.
2- Adams, K., O'Shea, J. P., O'Shea, K.L. and Climstein, M. (1992). The effect of six weeks of squat, plyometric and squat-plyometric training on power production. Journal of Applied Sports Science Research 6(1), 36-41.

\section{3- Bernd Barth \&Emil Beck} (2007): the complete guide to water polo . oxford: meyer \& meyer sport (UK) ltd.,

4- Blakey, J. B. and Southard, D. (1987). The combined effect of weight training and plyometrics on dynamic leg strength and leg power. Journal of Applied Sports Science Research 1, 14-16.

5- Cavagna G.A., Dusman B., Margaria R. (1968): Positive work done by previously stretched muscle. J Appl Physiolo 24:21-32.

6- Cavagna, G.A. (1977): Storage and utilization of elastic energy in skeletal muscle. Ererc. Sport Sci. Rev. 5:89-129.

7- Chu, D.A. (1998). Jumping into plyometrics. 2nd ed.Human Kinetics, Champaign, Ill.

8- Chui,E.F. (1964): Effects of isometric and dynamic weight training exercises upon 
strength and speed of movement. Research Quarterly 35:246-57.

9- Comyns, T.M., Harrison, A.J., Hennesey, L.K. and Jensen, R. (2007): Identifying the optimal resistive load for complex training in male rugby players. Sports Biomechanics 6, 59-70.

10- Crameri RM, Aagaard P, Qvortrup K, Langberg $H$, et al. (2007): Myofibre damage in human skeletal muscle: effects of electrical stimulation versus voluntary contraction. J Physiol.583:365-80.

11- Delecluse, Christophe. (1997): Influence of strength training on sprint running performance. Sports Medicine 24(3):147-56.

\section{2- Dengel, D.R., George,} T.W., Bainbridge, C., Fleck, S.J., Van Handel, P.J. and J.T. Kearney. (1987). Training responses in national team boxers. Medicine and Science In Sports and Exercise 19(2): 277.

\section{3- Diallo, O., Dore, E.,} Duche, P. and Van Praagh, E. (2001). Effects of plyometric training followed by a reduced training programme on physical performance in prepubescent soccer players. Journal of Sports Medicine and Physical Fitness 41(3), 342-348.

14- Ebben, W.P. and Blackard, D. (1998). Paired for strength: A look at combined weight training and plyometric training with an emphasis on increasing the vertical jump. Training and Conditioning 8(3), 55-63.

15- Ebben, W.P. and Watts, P.B. (1998). A review of combined weight training and plyometric training modes: Complex training. Strength and Conditioning. 20 (5),18-27.

16- Evans, A.K., Hodgkins, T.D., Durham, M.P., Berning, J.M., and Adams, K.J. (2000). The acute effects of a 5RM bench press on power output. Medicine and Science in Sport and Exercise 32(5), S311.

17- Fatourous, I.G., Jamurtas, A.Z., Leontsini, D., Taxildaris, K., Aggelousis, N., Kostopoulos, N. and Buckenmeyer, P. (2000). Evaluation of plyometric exercise training, weight training, and their combination on vertical jump and leg strength. Journal of Strength 
Conditioning Research 14 (4),470-476.

18- Ferrauti A, Neumann G, Weber K, Keul J. (2001). Urine catecholamine concentr ations and psychophysical stress in elite tennis under practice and tournament conditions. J Sports Med Phys Fitness; 41:269-74.

19- Fox,E.L., Bowers, R.W. and M.L. Foss. (1988)" The physiological basis of physical education and athletics, 4th ed. Dubuque, IA:William C. Brown.

20- Hamza, A.(2008). Effect of complex training on SOD gene expression, certain physical variables and performance level of lung and flech for young water polo players. Unpublished $\mathrm{PhD}$ thesis .Faculty of Physical Education .Zagazig University.

21- Hawke, T.J. (2005): Muscle Stem Cells and Exercise Training. Exerc. Sport Sci. Rev., Vol. 33, No. 2, pp. 63-68,

22- Kadi, F. and L.E. Thornell. (2000): Concomitant increases in myonuclear and satellite cell content in trapezius muscle following strength training. Histochem. Cell Biol. 113:99 -103

23- Lukovich I. (1997): Water polo: the Modern International Style. Staten Island, NY. SKA Swordplay Books.

24- McLaughlin, E.J. (2001): A comparison between two training programs and their effects on fatigue rates in women. Journal of Strength Conditioning Research .15 (1), 25-29.

25- Petrella JK, Kim JS, Cross JM, Kosek DJ, et al. (2006): Efficacy of myonuclear addition may explain differential myofiber growth among resistance-trained young and older men and women. Am J Physiol. 291:E937-46.

26- Rahimi, R., \& Behpur, N. (2005): The effects of plyometric, weight and plyometric-weight training on anaerobic power and muscular strength. J. Physical Education and Sport, 3 (1), 81 - 91.

27- Ransford CP. (1982). A role for amines in the antidepressant effect of exercise: a review. Med Sci Sport Exerc ;4:1-10.

28- Sale, D.G. (1991). Testing strength and power. In 
Physiological Testing of the High-performance Athlete (edited byJ.D. MacDougall, H.A. Wenger and H.J. Green), pp. 21-106. Champaign, IL: Human Kinetics.

29- Sandri M, Adams V, Gielen S, Linke A, et al. (2005). Effects of exercise and ischemia on mobilization and functional activation of bloodderived progenitor cells in patients with ischemic syndromes: results of 3 randomized studies. Circulation. 111:3391-9.

30- Vossen, J.F., Kramer, J.F., Burke, D.G. and Vossen, D.P. (2000). Comparison of dynamic push-up training and Plyometric push-up training on upper body power and strength. Journal of Strength Conditioning Research 14(3), 248-253. 